\title{
Impact of HIV infection and smoking on lung immunity and related disorders
}

\author{
Theresa M. Rossouw ${ }^{1,2}$, Ronald Anderson ${ }^{1}$ and Charles Feldman ${ }^{3}$ \\ Affiliations: \\ ${ }^{1}$ Department of Immunology, Faculty of Health Sciences, Institute of Cellular and Molecular Medicine, \\ University of Pretoria, Pretoria, South Africa. \\ ${ }^{2}$ Department of Family Medicine, Faculty of Health Sciences, University of Pretoria, Pretoria, South Africa. \\ ${ }^{3}$ Division of Pulmonology, Department of Internal Medicine, Charlotte Maxeke Johannesburg Academic \\ Hospital and Faculty of Health Sciences, University of the Witwatersrand, Johannesburg, South Africa.
}

\section{Correspondence:}

Theresa M. Rossouw, Dept Immunology, University of Pretoria, P.O. Box 2034, Pretoria, Gauteng, South Africa 0001.

E-mail: theresa.rossouwdup.ac.za

ABSTRACT HIV-infected persons not only have higher rates of smoking than the general population, but are also unusually vulnerable to the associated adverse health effects, both infective and noninfective in origin. Indeed, in the setting of well-organised care and availability of highly active antiretroviral therapy, HIV-infected smokers lose more life-years to smoking than to HIV infection per se, presenting a major challenge to healthcare providers. Not surprisingly, the respiratory system is particularly susceptible to the damaging interactive chronic inflammatory and immunosuppressive effects of HIV and smoking, intensifying the risk of the development of opportunistic infections, as well as lung cancer and obstructive lung disorders. The impact of smoking on the immunopathogenesis and frequencies of these respiratory conditions in the setting of HIV infection, as well as on the efficacy of antiretroviral therapy, represent the primary focus of this review.

@ERSpublications

Smoking exacerbates the immunosuppressive/pro-inflammatory effects of HIV, increasing the risk of pulmonary disease http://ow.ly/Oe9hE 


\section{Introduction}

50 years after the release of the first report by the United States Surgeon General on the health effects of smoking, tobacco use continues to pose a massive public health burden. It remains the single largest preventable cause of death and disease in both men and women, killing nearly 6 million people annually, including 600000 nonsmokers exposed to second-hand smoke [1]. Tobacco use caused $\sim 100$ million deaths in the 20th century and, if current trends continue, this number may increase to 1 billion deaths in the 21 st century. However, these official rates may be an underestimate, since recent research has shown that $\sim 17 \%$ of the excess mortality among smokers is attributable to causes not previously known to be associated with smoking [2].

Currently, in excess of 1.1 billion people in the world smoke. Despite the seemingly encouraging estimates of global modelling, which projected that smoking prevalence should have decreased between 1980 and 2012, in reality the opposite is true. The estimated prevalence was offset by the considerable population growth during this period, with the total number of regular smokers and cigarettes consumed increasing [3]. In addition, over the past two decades the global burden of disease attributable to tobacco smoking has not changed, since decreases in high-income regions have been tempered by increases in regions such as southeast Asia [4]. While Asia is currently the epicentre of the tobacco epidemic, Africa presents the greatest threat in terms of potential growth in tobacco consumption [4], converging with the HIV pandemic.

Globally, an estimated 35 million (range 33.2-37.2 million) people were living with HIV in 2013, and despite enormous achievements in treatment resulting in 12.9 million of these having begun highly active antiretroviral treatment (HAART), as well as some advances in prevention, new infections continued at a rate of $\sim 5800$ daily, totalling 2.1 million (range 1.9-2.4 million) annually worldwide. Notably, HIV-infected individuals appear to smoke more than the general population. For example, studies in European and North American HIV-infected cohorts report a smoking prevalence ranging from $40 \%$ to $>70 \%$, two to three times that of the general population [5-11]. Notwithstanding the increased prevalence of smoking, HIV-infected smokers have a significant, albeit unexplained, increased mortality and decreased quality of life compared to HIV-uninfected smokers [12]

A major impact of HIV infection is on the respiratory system [13]. This includes the occurrence of both communicable diseases, notably tuberculosis (TB), community-acquired pneumonia (CAP) and Pneumocystis jirovecii pneumonia (PCP), as well as noncommunicable conditions such as obstructive lung diseases and lung cancer. All these conditions are associated with concomitant cigarette smoking, with the risk seemingly greater in HIV-infected patients $[14,15]$. Some have even suggested that we are witnessing the convergence of several epidemics, namely smoking, HIV infection, TB, other respiratory infections, obstructive lung disease and lung cancer $[16,17]$. While opportunistic respiratory infections associated with advanced immunosuppression dominated the initial clinical picture in the setting of HIV infection, latterly, with the use of HAART, there has been a rise in deaths related to non-AIDS-defining illnesses, largely driven by the high rate of smoking among these individuals $[15,18]$. In fact, in those areas where HIV care is well organised and HAART is freely available, HIV-infected smokers lose more life-years to smoking than to HIV infection per se, the risk being considerable and often attributable to non-AIDS-defining conditions $[12,15,18,19]$.

The impact of cigarette smoking on the immunopathogenesis and occurrence of these respiratory conditions in the setting of HIV infection, as well as on the efficacy of antiretroviral therapy, represent the primary focus of the current review and does not extend to other tobacco products.

\section{Immunosuppressive mechanisms of HIV infection and smoking} HIV and pulmonary host defences

HIV infection has been described as a "disease of secondary lymphatic tissues", characterised by massive early depletion of the $\mathrm{CD}^{+}$, CCR5-expressing memory T-cell population in the gastrointestinal tract (GIT) [20], with the T-helper (Th)17 subset particularly vulnerable [21]. Although T-cell repopulation of the GIT ensues, the recovery is only partial, due to several mechanisms, including defective production of the homing cytokine CXCL25 by epithelial cells and dendritic cells, impeding the trafficking of gut-homing Th17 cells [22].

In contrast to the GIT, the lung appears relatively resistant to the early HIV-mediated depletion of CD4 ${ }^{+} \mathrm{T}$-cells $[21,23]$. This has been attributed to several mechanisms, including 1) resilience of airway Th1 and Th17 cells $[21,23]$ as well as large, as opposed to small, alveolar macrophages [24] to HIV infection and dysfunction; 2) relatively high frequencies of mucosal HIV-specific polyfunctional $\mathrm{CD} 4^{+} \mathrm{T}$-cells in the lungs; 3 ) a lesser mass of HIV-susceptible secondary lymphoid tissue relative to that of the GIT [20]; and 4) the apparent efficacy of the pulmonary HIV-specific cytotoxic T-cell response, manifested clinically as an alveolitis [25].

Nonetheless, these adaptive and innate pulmonary host defences progressively deteriorate, being ultimately subdued, with those mechanisms described in the following section seeming to be the most prominent contributors to HIV-mediated immune attrition/exhaustion. 
Immunosuppression due to HIV infection of $\mathrm{CD} 4^{+} \mathrm{T}$-cells

$\mathrm{HIV}$ is directly cytopathic for $\mathrm{CD}^{+}{ }^{+} \mathrm{T}$-cells with the memory subset more susceptible than naïve cells $[25,26]$. Abortive infection of quiescent "bystander" $\mathrm{CD} 4^{+} \mathrm{T}$-cells is also believed to be a major cause of T-cell depletion. In this setting, incomplete HIV reverse transcripts (DNA) accumulate in the cytosol. These, in turn, are recognised by the interferon- $\gamma$-inducible viral cytosolic DNA receptor, IFI16, which forms an inflammasome, resulting in the activation of a caspase-1-mediated intense inflammatory response leading to a type of inflammation-associated cell death known as pyroptosis [27]. These generalised mechanisms of cell death are exacerbated by destruction of HIV-infected $\mathrm{CD}^{+}{ }^{+}$T-cells by HIV-antigen-specific $\mathrm{CD} 8^{+}$cytotoxic T-cells.

Follicular helper T-cells (Tfh) are extremely vulnerable to infection by HIV. These cells, which populate the germinal centres of secondary lymphoid organs, including the highly-organised network of mediastinal lymph nodes in the lung, promote B-cell maturation and isotype switching [28]. Infection of Tfh cells by HIV not only compromises the production of specific antibodies, but also serves as a major reservoir of the virus [28].

\section{$C D 4^{*} T$-cell depletion due to chronic immune activation}

Prolonged exposure of $\mathrm{CD}^{+}$T-cells to HIV-derived proteins such as $\mathrm{Vpr}$ and Tat, as well as to the family of common $\gamma$-chain cytokines (interleukin (IL)-2, -4, -7, -9, -15 and -21), represent generalised mechanisms of apoptosis mediated by various pathways [29-32]. These include Fas/Fas ligand, tumour necrosis factor (TNF)/TNF receptor-1/-2, TNF-related apoptosis-inducing ligand/death receptors $4 / 5$ and others, programmed death receptor (PD)-1 and its ligand (PD-L1) and apoptotic microparticles released from apoptotic cells [29-32]. In this context, it is noteworthy that relative to the circulation, the numbers of total and HIV-specific $\mathrm{CD}^{+}$and $\mathrm{CD}^{+}$T-cells in the lung, although significantly elevated, display a dysfunctional phenotype associated with increased expression of PD-1 [33].

In addition, persistent production of interferon- $\alpha$ and indoleamine 2,3-dioxygenase by chronically activated plasmacytoid dendritic cells, which populate the lungs and other sites such as the GIT and bone marrow, not only promotes apoptosis of $\mathrm{CD}^{+}$and $\mathrm{CD}^{+}$T-cells, but also induction of immunosuppressive regulatory T-cells (Tregs) [34]. This results predominantly from the interaction of viral nucleic acid with the intracellular Toll-like receptor (TLR)7, and possibly with TLR9, as well as cytoplasmic pathogen nucleic acid sensors [34].

\section{HIV-associated systemic activation of monocytes and neutrophils as a cause of immunosuppression}

Chronic systemic activation of monocytes [29, 35] and neutrophils [36, 37] by HIV and its proteins, as well as exposure to pro-inflammatory microbial products (DNA and lipopolysaccharide) originating from a damaged GIT by the process of microbial translocation [35] (fig. 1) also contribute to immunosuppression. In the case of monocytes, trafficking of these cells to the lungs is likely to drive T-cell apoptosis and dysfunction via the release of pro-inflammatory cytokines and reactive oxygen species (ROS) [29, 35]. Neutrophils also acquire an activated phenotype characterised by increased production of ROS, release of arginase and expression of PD-L1, driving T-cell dysfunction and death [36, 37]. As described later, phagocyte-derived ROS are also potential carcinogens. In addition, the numbers of circulating myeloid suppressor cells, seemingly of granulocytic origin, rise steadily as HIV infection progresses [37, 38], increasing susceptibility to development of infection and oncogenesis.

\section{Transforming growth factor- $\beta 1$}

Chronic immune activation during HIV infection results in increased production of the immunosuppressive cytokine, transforming growth factor (TGF)- $\beta 1$, by various types of immune, inflammatory and structural cells [39]. Although intended to counter chronic immune activation [40, 41], TGF- $\beta 1$ contributes to HIV-related immunosuppression by several mechanisms, including 1) induction of the transcription factor, Foxp3, a key event in the development of Tregs [39] and 2) promotion of collagen deposition and fibrosis in secondary lymphoid tissues, disrupting T-cell colonisation and function [20]. TGF- $\beta 1$ has also been implicated in the pathogenesis of various types of cancer, including lung cancer [42, 43]. In addition, TGF- $\beta 1$, via pro-fibrotic activity, may also contribute to the development of chronic obstructive pulmonary disease (COPD) [44]. It is noteworthy that, even in the setting of HAART-mediated viral suppression, circulating levels of TGF- $\beta 1$ remain elevated, consistent with ongoing chronic immune activation [41].

These immunosuppressive mechanisms are summarised in figure 2 .

\section{Smoking and immunity}

Similarities exist between the effects of HIV infection and those of smoking on immune reactivity. The wide-ranging suppressive effects of smoking, encompassing both innate and adaptive airway host defences, have been described elsewhere [45] and are summarised in figures 1 and 2 and table 1. These 


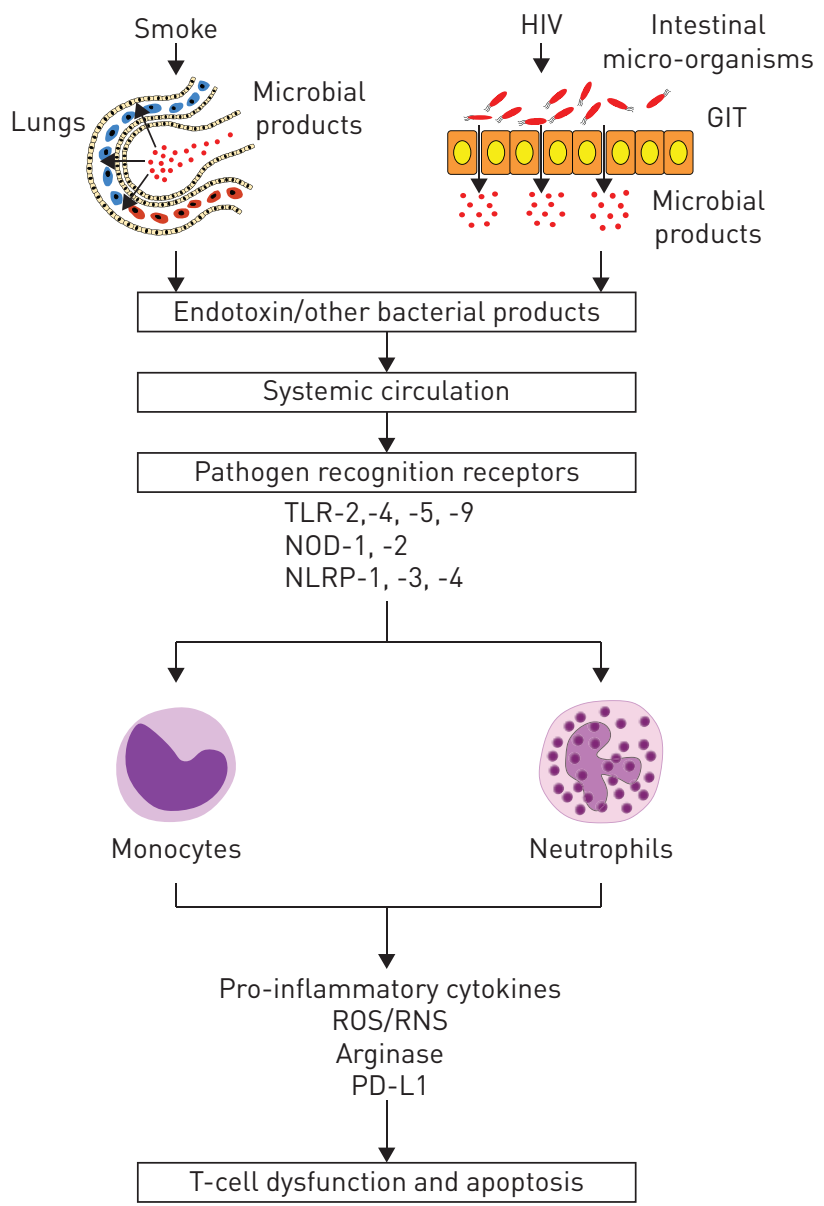

FIGURE 1 Proposed mechanisms by which cigarette smoking and HIV infection cause translocation of pro-inflammatory microbial products from the lungs and gastrointestinal tract (GIT). Smoking and HIV infection result in increased alveolar epithelial and intestinal epithelial permeability, respectively, with consequent translocation of bacterial endotoxin and other microbial products derived from tobacco/cigarette smoke and enteric micro-organisms. These microbial products interact with various types of pathogen recognition receptors (PRRs), such as the Toll-like receptors (TLRs)-2, $-4,-5$ and -9 , nucleotide oligomerisation domain-like receptors (NODs)-1, -2 and NOD-like receptor pyrin domain-containing (NLRP)-1, -3 and -4 expressed on/in various types of immune inflammatory cells, especially monocytes and neutrophils. PRR-mediated recognition of endotoxin and other microbial products results in the systemic activation of these cells, leading, in turn, to the synthesis/release of various pro-inflammatory/apoptosis-inducing/immunosuppressive cytokines (interleukin-1 $\beta,-6,-8$, tumour necrosis factor and others), reactive oxygen and nitrogen species (ROS/RNS) and the granule enzyme arginase, as well as upregulation of expression of the programmed death ligand 1 (PD-L1) on neutrophils, all of which contribute to $\mathrm{CD}^{+}$T-cell dysfunction and apoptosis.

immunosuppressive and pro-inflammatory effects of smoking result from constant exposure of the airways to the vast array of low molecular toxicants generated during the combustion of tobacco. These include various hydrocarbons, gases, highly reactive free radicals and heavy metals [45]. Tobacco also contains various pro-inflammatory microbial products, including bacterial endotoxin, which remain biologically active in cigarette smoke, albeit at a lower level [46, 47]. Prolonged exposure to the cytotoxic and pro-inflammatory agents in cigarette smoke results in chronic inflammation, oxidative stress and immunosuppression, increasing susceptibility to respiratory infection, particularly with the bacterial pathogens, Streptococcus pneumoniae and Mycobacterium tuberculosis [45]. Notwithstanding suppression of pulmonary host defences [48], smoking also poses the risk of damage to lung epithelium and endothelium, facilitating extrapulmonary dissemination of microbial pathogens and possibly entry of HIV [49, 50].

Like HIV infection [36, 37, 51], smoking causes a chronic, low-grade, systemic inflammatory response characterised by increased numbers of activated neutrophils in the circulation and lungs [52, 53]. Smoking-related systemic inflammation has been attributed to extrapulmonary dispersal of the neutrophil-mobilising cytokines, IL-1 $\beta$, IL-6, TNF and granulocyte-macrophage colony-stimulating factor, as well as the chemokine IL-8 produced by resident airway cells [52, 53]. Smokers also have higher levels of circulating bacterial endotoxin than nonsmokers, although the origins (tobacco or tobacco smoke or leakage 


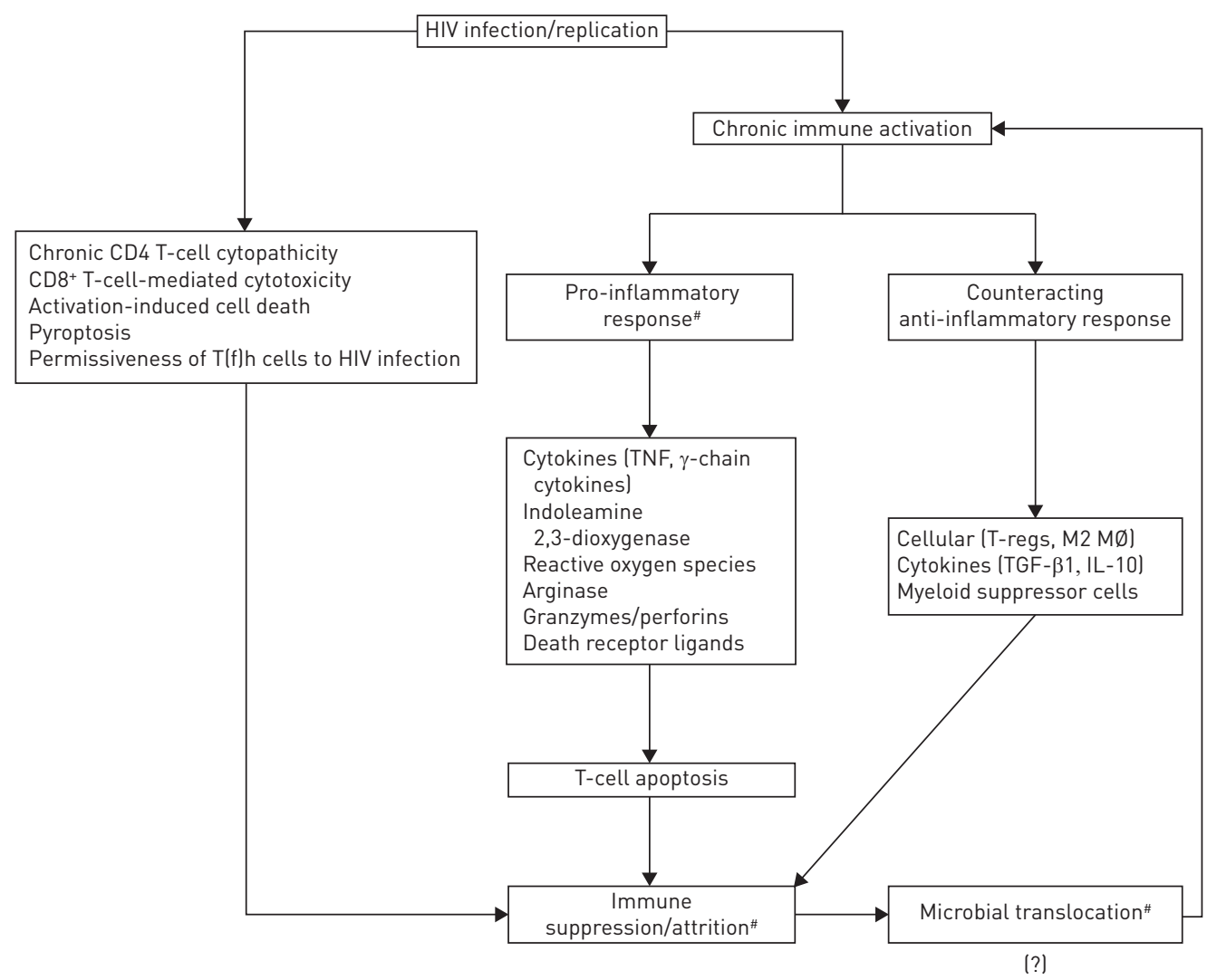

FIGURE 2 Proposed mechanism by which HIV infection causes chronic depletion of $\mathrm{CD}^{+} \mathrm{T}$-cells and progressive immune attrition. Notwithstanding HIV-mediated $\mathrm{CD}^{+}$T-cell cytopathicity and destruction of these cells by HIV-specific $\mathrm{CD}^{+}$cytotoxic T-cells, chronic exposure to viral antigens also results in activation-induced cell death and pyroptosis of bystander cells due to intracellular accumulation of incomplete viral DNA reverse transcripts. The permissiveness of follicular helper T-cells (Tfh cells) to HIV infection also favours viral persistence and immune dysfunction (decreased production of specific antibodies). These various mechanisms of $\mathrm{CD}^{+} \mathrm{T}_{\text {-cell }}$ death and dysfunction are exacerbated by the highly pro-inflammatory environment created by HIV infection in the lung land other body compartments). In turn, this results in the unrelenting exposure of pulmonary $\mathrm{CD4}^{+} \mathrm{T}$-cells to a range of pro-apoptotic mediators derived from both resident and infiltrating immune/inflammatory and structural cells. These include tumour necrosis factor (TNF) and $\gamma$-chain cytokines released by various cell types; interferon- $\alpha$ and indoleamine 2,3-dioxygenase derived from plasmacytoid dendritic cells; reactive oxygen species and arginase from neutrophils and monocytes/macrophages; granzymes and perforins from $\mathrm{CD}^{+}$cytotoxic T-cells and other types of "killer cells"; and death receptor ligands released by/present on various types of resident and infiltrating immune/inflammatory cells. These interacting mechanisms, exacerbated by microbial translocation and smoking, sustain a self-perpetuating "vicious cycle" of chronic immune activation/inflammation, $\mathrm{CD}^{+} \mathrm{T}$-cell death and immunosuppression. Acquired immunodeficiency is worsened by an ongoing ineffectual counteracting anti-inflammatory response involving regulatory T-cells (Tregs) and macrophages of the M2 phenotype and their associated cytokines, transforming growth factor (TGF)- $\beta 1$ and interleukin (IL)-10, as well as myeoloid suppressor cells. \#: immunosuppressive/inflammatory mechanisms potentiated by smoking, although the effects of smoking on microbial translocation remain to be established conclusively, as denoted by (?).

from the GIT) are unknown [54]. Ongoing neutrophil-mediated systemic inflammation and endothelial activation [55] are potential contributors to the unusually high frequency of COPD and lung cancer in HIV-infected individuals who smoke $[15,56]$.

TABLE 1 Innate and adaptive pulmonary host defence mechanisms impaired by smoking [45]

Innate defences

Adaptive defences
Mucociliary clearance, epithelial barrier function, production of antiviral and antimicrobial proteins by respiratory epithelium

Phagocytic activity of small alveolar macrophages

Antigen-presenting activities of pulmonary dendritic cells

Antiviral activities of plasmacytoid dendritic cells

Antitumour and antiviral activities of natural killer cells

Production of specific antibodies

Cell-mediated immunity (production of interferon- $\gamma$ ) 
As with HIV infection, smoking has been reported to cause increased production of TGF- $\beta 1$, in this case localised to the lungs of both ostensibly healthy smokers and, especially, those with COPD [57]. In this setting, TGF- $\beta 1$ was found to originate from small airway epithelium and was inversely correlated with small airway obstruction [57]. However, biologically interactive effects of HIV and smoking on pulmonary and systemic levels of TGF- $\beta 1$ have not been described.

\section{Cumulative effects of HIV infection and smoking on immunity}

Increased permissiveness of the alveolar macrophages of smokers to HIV infection and replication in vitro have been described [58], while exposure of isolated human microglial cells [59] or TZM-bl (CD4/CCR5 co-expressing HeLa cells) and Jurkat T-cell lines [60] to nicotine or cigarette smoke extract, respectively, also augments HIV infectivity. However, to our knowledge no studies have reported possible cumulative immunosuppressive effects of HIV infection and smoking on functional indices of immune reactivity in HAART-naïve subjects. The closest are two recent reports, largely in the setting of virally suppressive HAART, in which smoking was associated with significant elevations in cellular and soluble biomarkers of systemic immune activation/exhaustion/dysfunction $[54,61]$. The first of these described increased expression of CD38 and HLA-DR, as well as PD-1/T-cell immunoglobulin mucin-3/cytotoxic T-lymphocyte-associated protein-4, markers of immune activation and exhaustion, respectively, on both $\mathrm{CD} 4^{+}$and $\mathrm{CD}^{+} \mathrm{T}$-cells of HIV-infected smokers [54]. Because these effects of smoking were associated with raised levels of circulating bacterial endotoxin, the authors proposed that smoking, like HIV infection, causes microbial translocation with consequent augmentation of systemic immune activation [54]. However, this contention can be challenged on two fronts. Firstly, the levels of circulating bacterial endotoxin were comparable in HIV-infected smokers and nonsmokers [54], and secondly, as mentioned earlier, endotoxin is present in both tobacco and tobacco smoke [46, 47].

The second study compared the numbers and reactivities of pulmonary mucosal and circulating $\mathrm{CD}^{+}{ }^{+}$and $\mathrm{CD}^{+}{ }^{+}$T-cells from HIV-infected subjects, many of whom were current smokers and mostly on HAART, with and without COPD, a condition for which both HIV and smoking are major risk factors [61]. Relative to the $\mathrm{HIV}^{+} / \mathrm{COPD}^{-}$group, as well as to an $\mathrm{HIV}^{-} / \mathrm{COPD}^{+}$control group, the authors observed significant, selective depletion of pulmonary mucosal $\mathrm{CD}^{+} \mathrm{T}$-cells, including memory and polyfunctional cells, in the $\mathrm{HIV}^{+} / \mathrm{COPD}^{+}$subjects. This was associated with deficient responses of mucosal $\mathrm{CD}^{+}{ }^{+} \mathrm{T}$-cells to both HIV- and bacteria-derived antigens in the setting of increased co-expression of the pro-apoptotic markers Fas death receptor and PD-1 [61]. Although consistent with activation-induced cell death and immune exhaustion, possibly related to a biologically interactive effect of HIV and smoking, this interpretation is complicated by the high number of current smokers in the $\mathrm{HIV}^{+} / \mathrm{COPD}^{-}$group and lack of inclusion of numbers of ex-smokers in both HIV-infected groups, as well as data on the use of inhaled corticosteroids and duration of HAART. However, interestingly, the median smoking history (pack-years) was shorter, albeit not significantly so, in the $\mathrm{HIV}^{+} / \mathrm{COPD}^{-}$group relative to the $\mathrm{HIV}^{+} / \mathrm{COPD}^{+}$group (8.45 versus 13.4 pack-years), suggesting that early administration of HAART to HIV-infected smokers may slow the development of COPD. Although speculative, this contention is supported by findings that the lung is more responsive than the vascular compartment to the virally suppressive actions of HAART, with a more rapid decline in HIV viral load in both the acellular compartment and alveolar cells [62]. This is paralleled by partial immunorestoration, associated with decreased numbers and activation status of pulmonary $\mathrm{CD}^{+} \mathrm{T}$-cells, and a gradual increase in the numbers of $\mathrm{CD} 4^{+} \mathrm{T}$-cells in the setting of decreased concentrations of pro-inflammatory cytokines/chemokines [62].

However, the most compelling evidence in support of a cumulative, immunosuppressive effect of HIV infection and smoking is derived from clinical epidemiological studies demonstrating increased frequencies and severity of TB, PCP and pneumococcal pneumonia in HIV-infected smokers, described later in this review.

\section{Effects of smoking on HIV disease progression and treatment}

Research has yielded inconsistent results on the effects of smoking on HIV disease progression and outcome of antiretroviral treatment. It is known that the number of circulating leukocytes is directly related to cigarette consumption, with HIV-uninfected smokers having higher total white cell counts than nonsmokers: so-called "smoker's leukocytosis" [63]. This effect is nonspecific, affecting all leukocyte types, including $\mathrm{CD}^{+} \mathrm{T}$-cells. Some authors have suggested that the specific leukocyte population affected is dependent on the amount of smoking, with light smokers having a higher, and heavy smokers a lower $\mathrm{CD}^{+}$to $\mathrm{CD}^{+}$ratio [64]. Nevertheless, this difference is attenuated at the time of HIV seroconversion and disappears after 3 years [65].

Some studies have shown that smokers have a more rapid loss of $\mathrm{CD} 4^{+} \mathrm{T}$-cells during the course of HIV infection [11,66] and an increased likelihood or rate of progression to AIDS [66,67]. Such a contention is plausible based on findings that the magnitude of HIV replication is a strong predictor of the rate of progression to AIDS [68] and is supported by several in vitro studies, mentioned earlier, which have 
shown that smoking enhances HIV-1 replication in alveolar macrophages, microglia and T-cells [58-60]. It has been suggested that iron and oxidative stress are possible mechanisms of enhanced production of HIV-1 by alveolar macrophages in cigarette smokers $[69,70]$. In contrast, a number of clinical studies has failed to confirm accelerated disease progression in smokers [71-78], most probably because they were restricted to specific high-risk groups, such as men who have sex with men and injection-drug users. Given that smoking may be correlated with other high-risk sexual or drug use behaviour, these studies are troubled by the possibility of confounding and future studies should seek to include epidemiologically appropriate control groups with comparable risk profiles and a wider spectrum of participants [79].

With regard to therapy, smoking may be associated with decreased efficacy of HAART, resulting in both immunological and virological failure $[11,80]$. One study has shown that long-term smoking attenuated the immunological and virological responses to HAART by $40 \%$ [80]. These findings are supported by the Women's Interagency HIV Study, which also reported that women who smoked while on HAART had significantly higher morbidity (AIDS-defining conditions hazard ratio (HR) 1.36, $\mathrm{p}=0.01$ ) and mortality (HR 1.53, p=0.018) than nonsmokers, and that HAART may be less effective in these patients. Smokers had a lower chance of achieving a viral (HR 0.79, $\mathrm{p}=0.006$ ) or immunological response (HR 0.85, $\mathrm{p}=0.041$ ), and a greater chance of developing viral (HR 1.39, $\mathrm{p}=0.013$ ) or immunological failure (HR 1.52, $\mathrm{p}=0.001$ ) [11]. In this study, significantly more smokers were African-American, used illicit drugs or had a lifetime history of illicit injection drug use, were infected with hepatitis $\mathrm{C}$ virus, had previously been diagnosed with AIDS and had lower levels of adherence. Although this analysis controlled for possible confounders, unidentified residual influences cannot be excluded.

Notwithstanding the counteracting immunosuppressive effect of HIV/smoking on the efficacy of therapy, other possible causes of smoking-related interference with HAART include 1) smoking is a surrogate marker of a noncompliant disposition [81, 82]; 2) higher frequencies of side-effects in smokers, including neuropsychiatric symptoms associated with efavirenz-based HAART regimens [83]; 3) negative effects of smoking-related activation of cytochrome P450 enzymes, such as the CPY1A1-m1 variant, which promote oxidative conversion of smoke-derived toxicants to DNA adducts, causing activation of genes that support HIV replication [70, 84]; 4) altered pharmacokinetics of antiretroviral agents, possibly related to smoking-mediated induction of CYP3A4 and aryl-hydrocarbon-hydroxylases [85, 86], which metabolise many protease and non-nucleoside reverse transcriptase inhibitors [87, 88]; and 5) smoking-induced mitochondrial oxidative stress [89], which may exacerbate the adverse effects of antiretroviral drugs that induce mitochondrial toxicity, such as drugs from the nucleoside reverse transcriptase inhibitor class [90].

Smokers may also be at heightened risk for developing HIV-associated drug resistance due to smoking/ oxidative stress-associated increased activity of nuclear transcription factor $\kappa \mathrm{B}$ [91], driving both viral transcription and diversity [92]. However, this remains to be proven in the clinical setting.

\section{Clinical consequences of the cumulative effects of HIV infection and smoking on the major HIV-associated pulmonary conditions \\ Pulmonary infections \\ Community-acquired pneumonia}

It is well recognised that smoking is an independent and eminently preventable risk factor for the development of CAP in both HIV-infected and -uninfected individuals [13, 93-99]. In HIV-infected patients, the increased risk for CAP, which is evident at all levels of immunosuppression, is estimated to be between two- and five-fold, increasing as the CD4 cell count declines [13, 100]. Although rates of CAP in HIV-infected individuals have decreased since the introduction of HAART, they nevertheless remain higher than in HIV-uninfected persons, with smoking a major and persistent risk factor [14, 94, 99].

S. pneumoniae is the most common cause of CAP in both HIV-infected and -uninfected patients, accounting for $\sim 20 \%$ of cases of all-cause bacterial pneumonia, $40 \%$ of cases of CAP in which a specific pathogen is identified and $70 \%$ of cases of bacteraemic pneumonia $[13,97,100]$. The rates of invasive pneumococcal disease (IPD) associated with HIV infection are estimated to be up to 100-fold higher compared to HIV-uninfected persons [97]. Predictably, smoking, as well as alcohol abuse, are also significant risk factors for IPD, with both these harmful lifestyle aspects over-represented in those infected with HIV [100, 101].

Importantly, cessation of cigarette smoking by HIV-infected individuals significantly decreases the risk of development of IPD and other pneumococcal infections, irrespective of the degree of immunodeficiency [99, 101-104].

\section{Tuberculosis}

Mounting evidence from a number of countries in both the developed and developing worlds attests not only to the predisposing effect of smoking for the development of pulmonary TB [105-112], but also for 
more severe disease progression [113], decreased efficacy of antimicrobial chemotherapy [114], prolonged infectivity [115-117], recurrence of disease [118], poor outcomes of multidrug-resistant TB [119] and possibly impaired post-treatment lung function [120].

The link between TB and HIV infection is also well established, with TB recognised as the most important opportunistic infection in HIV-infected patients in both sub-Saharan Africa and other regions of the developing world [16]. Long-term smoking has been reported to double the risk of TB in HIV-seropositive patients on HAART [80]. Although somewhat under-researched, it has been reported that smoking is associated with a poor outcome for opportunistic infections in $\mathrm{HIV}$-infected patients, including TB [14, 16, 121].

With respect to TB therapy-related adverse events, one study reported a significantly increased risk (OR 2.00) in smokers [122]. In contrast, smoking has been reported to attenuate isoniazid-associated hepatotoxicity by increasing $N$-acetyltransferase 2 activity, with potential implications for efficacy of therapy [123]. Although the impact of smoking on the efficacy of combined HAART/TB therapy, as well as on the frequency of therapy-associated adverse effects, requires additional research, cessation of smoking simply on the basis of its negative effects on the individual types of therapy is clearly warranted.

\section{Pneumocystis jirovecii}

Cigarette smoking is also associated with an increased risk of PCP. In one study, after controlling for HIV status and HAART on multivariate analysis, cigarette smoking was documented to double the risk of developing PCP [80]. A subsequent study by the same investigators documented not only a high rate of tobacco use among $521 \mathrm{HIV}$-infected patients admitted to hospital (65\% being smokers, 40\% of whom smoked more than one pack of cigarettes per day), but also that tobacco use increased the risk of respiratory infections, including CAP, PCP, TB and nontuberculous mycobacterial infections [14]. HIV-infected smokers were three times more likely to be admitted to hospital with PCP even after controlling for HAART, viral load and CD4 cell count [14]. Importantly, in that study, the increased risk of hospitalisation for CAP and PCP was related in a dose-dependent manner to the number of cigarettes smoked per day. Another study investigating $P$. jirovecii colonisation in HIV-infected men documented not only a high rate of colonisation, but also identified cigarette smoking as an independent risk factor for colonisation [124]. The authors concluded that the increased rates of colonisation in smokers, as well as being a potential source of $P$. jirovecii infection in the colonised individual, may also increase the risk of spread of the disease to others.

\section{Other infections}

The relationship between cigarette smoking in HIV-infected persons and other infections is less well established. Influenza is a common respiratory tract infection in the general population and cigarette smoking has been shown to increase both the risk and severity of infection [64, 125-129]. However, the situation with regard to risk in HIV-infected individuals of both seasonal and pandemic influenza is less clear-cut, whether in smokers or in nonsmokers [100]. One study from South Africa documented that influenza-related acute lower respiratory infections were approximately eight-fold more common in HIV-infected persons compared with HIV-uninfected cases [130]. This was associated with a higher frequency of influenza B than influenza A, a greater risk of pneumococcal co-infection and a higher mortality; however, there was no difference in smoking prevalence between the two groups of patients [130]. With respect to fungal infections, strong associations between smoking and infection with Cryptococcus neoformans and C. gattii have been described in both HIV-infected and -uninfected individuals [131, 132].

\section{Noninfective pulmonary conditions \\ Lung cancer}

Much has been written about the occurrence of lung cancer in HIV-infected patients, with initial studies variously documenting it to be increased, decreased or the same in HIV-infected patients, compared to the general population [133-141]. More recently, several studies have suggested that there is indeed an increased incidence of lung cancer in HIV-infected patients, especially evident in the post-HAART era and associated with a poor outcome [134-138, 140, 141], with the adjusted risk ranging from 2.0 to 7.0 [18]. This increased risk may relate, at least in part, to the fact that HIV-infected persons, especially intravenous drug users, tend to smoke more than the general population $[135,138]$. This contention is supported by reports of a high frequency of lung cancer in HIV-infected persons who smoke, as opposed to those who do not $[135,139]$.

Conversely, several studies have reported that the incidence of lung cancer in HIV-infected individuals remains high even after adjustments for smoking or independently of smoking [133, 136-138]. In the largest cohort study conducted to date, involving 110000 veterans, it was reported that HIV-infected cases had a significantly higher risk of lung cancer than HIV-uninfected cases, and that HIV was an independent risk factor for lung cancer after controlling for a number of confounding variables, including smoking 
[140]. Other studies have documented that lung cancer occurs at a younger age among HIV-infected individuals compared to the general population and at lower exposures to cigarette smoke [133].

Factors other than smoking that may play a role in the increased risk of lung cancer in the setting of HIV infection include HIV-related factors (e.g. oncogenic role of HIV and chronic immunosuppression) and increased susceptibility of HIV-infected persons to mutagens/carcinogens such as chronic inflammation-derived ROS and possibly antiretroviral agents [135, 141]. However, the role of immunosuppression is unclear, with several studies suggesting involvement $[136,139]$, while others have presented evidence to the contrary [138].

Notably, colonisation with $P$. jirovecii has been reported in patients with various chronic lung diseases, and aside from being involved in the development or transmission of this infection, may also be associated with the development of other lung conditions, such as lung cancer [142]. Some studies have documented high rates of colonisation with $P$. jirovecii in patients with lung cancer; one small study noted a colonisation rate of $100 \%$ in patients with small cell carcinoma, as compared to nonsmall cell cancer [142]. Other infections that have that been implicated in the pathogenesis of lung cancer include TB and Chlamydia pneumoniae infection $[143,144]$. The exact mechanisms by which chronic infections may induce cancer development are incompletely understood, but may be related, at least partly, to chronic inflammation, resulting in prolonged exposure of the airways to potentially carcinogenic phagocyte-derived ROS [56].

Clearly, the HAART-associated increase in life expectancy and high smoking rates among HIV-infected patients put them at increased risk of lung cancer, reinforcing the need for a programme of ongoing education and implementation of smoking cessation strategies [138].

\section{Obstructive lung disease (COPD and asthma)}

In the pre-HAART era, several studies suggested an association of HIV infection with an accelerated form of smoking-induced emphysema in which cytotoxic T-lymphocytes were considered to play an important role in pathogenesis $[145,146]$. In the HAART era, HIV plasma viral load has been shown to be independently associated with the development of COPD, possibly due to increased activation of CD8 T-cells [147]. Furthermore, two studies documenting the impact of smoking in HIV-infected persons have reported an increased frequency of COPD $[12,148]$. In the first study, COPD was much more common in current smokers (OR 5.25, 95\% CI 1.62-17.01) and ex-smokers (OR 5.25, 95\% CI 1.53-17.99) than in never-smokers [12], while in the second, HIV infection was documented to be an independent risk factor for COPD [148]. Interestingly, a number of studies have indicated that HIV infection is associated with the emphysema phenotype of COPD, further strengthening the suggestion of an overall association between HIV infection and COPD [149, 150].

Further studies are needed to determine whether HIV increases the susceptibility to COPD or rather accelerates the course of the disease [148]. Nevertheless, some have suggested that HIV-infected individuals may be especially susceptible to the effects of cigarette smoke [18]. This contention is supported by the recent study on pulmonary immune dysfunction in HIV-infected subjects with and without COPD [61], as well as by the findings from an earlier experimental study, that co-exposure of mice to a viral mimetic (synthetic double-stranded RNA) and cigarette smoke significantly augmented pulmonary inflammation, accelerating development of airway fibrosis and emphysema [151].

Recent research has also focused on the role of $P$. jirovecii colonisation in the pathogenesis and progression of COPD [141, 142, 152]. Although there is clearly an increased rate of colonisation with this pathogen in patients with COPD [142], the link may be purely an epiphenomenon related to structural lung damage and/or immunosuppression due to corticosteroid use. Nevertheless, it is possible that higher rates of airway obstruction in HIV-infected patients, even after adjustments for smoking, could be related aetiologically to both lung and systemic inflammatory responses associated with $P$. jirovecii colonisation [142].

Despite a number of reviews on the topic $[141,146,153,154]$, it remains difficult to determine whether COPD in the setting of HIV infection occurs as a consequence of higher rates of smoking, drug abuse, pulmonary infections or other risk factors, including occupational or environmental exposures, and low socioeconomic status [153]. These reviews have also focused on potential mechanisms that may be involved in $\mathrm{HIV}$-associated COPD, such as high-risk behaviour (including cigarette smoking), increased susceptibility to pulmonary infection and colonisation, aberrant inflammatory responses, altered oxidant/ antioxidant defences, increased apoptosis and effects of HAART [141, 146, 154]. Irrespective of the mechanisms involved in HIV-associated COPD, cessation of smoking as a preventive strategy is certainly a priority, while the role of early implementation of HAART remains to be established in this setting. In this regard the results of the pulmonary substudy of the Strategic Timing of Antiretroviral Therapy (START) study, which is comparing the effects of different timings of initiation of HAART, may help to elucidate whether early initiation of HAART has any impact on lung function in patients with HIV infection [155]. 
In addition to COPD, HIV infection has been found to be associated with an increased prevalence of small airway abnormalities, asthma and bronchial hyperresponsiveness, particularly among smokers [141, 153]. Prior to the introduction of HAART, it was said that asthma was common in patients with HIV infection, possibly related to smoking as well as atopy [141]. However, in the HAART era, findings regarding asthma incidence are somewhat contradictory; some studies have suggested that rates are higher than in the general population with patients reporting the onset of asthma in adulthood, often after the diagnosis of HIV infection [141].

\section{Other noninfective pulmonary conditions}

Although bronchiectasis appears to be more common in individuals who are HIV infected, there do not appear to be any studies investigating the role, if any, of cigarette smoking in its pathogenesis [156, 157]. Likewise, the contribution of smoking to the well-recognised association between HIV infection and predisposition for development of pulmonary hypertension [158] is also uncertain, with the exception of a single study which assessed the association between HIV, human herpesvirus-8, sociodemographic information (such as smoking) and pulmonary hypertension [159]. Although no effects of smoking were evident, interpretation is complicated by the high number of smokers in both the HIV-infected and -uninfected control groups and the lack of objective validation of self-reported smoking history.

\section{Circulating inflammatory biomarkers predictive of non-AIDS-defining pulmonary conditions}

Identification of biomarkers which predict development of, and/or mortality from non-AIDS-defining illnesses, including pulmonary disorders, in HIV-infected subjects on virally-suppressive HAART is a topic of considerable current interest [160]. Although few studies have addressed the influence of smoking in this setting, soluble (s)CD14 and TGF- $\beta 1$, both of which are affected by smoking and remain elevated in the face of virally suppressive HAART $[45,73,161,162]$, show promise. However, their clinical utility, as well as that of others, such as IL-6, high-sensitivity C-reactive protein, sCD163 and D-dimer as biomarkers in identifying HIV-infected individuals at high risk for development of non-AIDS-defining disorders and death, especially those who smoke, awaits acquisition of additional data from well-controlled, definitive studies.

\section{Potential adjunctive/anti-inflammatory therapies}

While HAART remains the cornerstone of treatment of HIV infection, persistent immune activation/chronic inflammation extending several years beyond the implementation of virally suppressive therapy [163], apparently exacerbated by smoking [54, 61], underscores the necessity for effective adjunctive/ anti-inflammatory strategies in this setting. Notwithstanding aggressive implementation of smoking cessation strategies, various therapies targeting chronic immune activation and inflammation which may ameliorate the long-term complications of HIV infection, especially in those who smoke, have been, or are currently being investigated (table 2) [164-166]. However, research has been restricted to small proof-of-concept trials and should be expanded to larger randomised clinical trials that can evaluate markers of immune activation, as well as clinical events, with special consideration of the outcomes in HIV-infected smokers.

TABLE 2 Potential adjunctive/anti-inflammatory therapies [164-166]

\begin{tabular}{ll} 
Strategy & Potential therapies \\
\hline Enhancing GIT mucosal repair & $\begin{array}{c}\text { Bovine serum colostrum, micronutrient } \\
\text { supplementation, pro- and pre-biotics } \\
\text { Rifaximin, sevelamer carbonate }\end{array}$ \\
$\begin{array}{l}\text { Reducing microbial translocation and endotoxin } \\
\text { Intensifying HAART }\end{array}$ & $\begin{array}{l}\text { Maraviroc and raltegravir } \\
\text { Treating co-infections }\end{array}$ \\
$\begin{array}{l}\text { Reducing activation of plasmacytoid dendritic cells } \\
\text { Decreasing TGF- } \beta 1 \text {-mediated lymph node fibrosis }\end{array}$ & $\begin{array}{l}\text { Pirfenidone, lisinopril } \\
\text { Immune modulators/anti-inflammatory agents }\end{array}$ \\
& HMG CoA reductase inhibitors, minocycline, \\
& selective cyclo-oxygenase-2 inhibitors, \\
Inhibiting caspase-1 activity and cleavage of pro-IL-1 $\beta$ & VX-765
\end{tabular}

GIT: gastrointestinal tract; HAART: highly active antiretroviral therapy; TGF: transforming growth factor; IL: interleukin; HMG CoA: 3-hydroxy-3-methylglutaryl-coenzyme A. 


\section{Conclusion}

Although entirely avoidable, it is abundantly clear that cigarette smoking further compromises a pulmonary immune system already ravaged by HIV, not only exacerbating the predisposition to life-threatening conditions of both infective and noninfective origin, but also countering the benefits of HAART. The magnitude of this problem and the need for prioritisation of effective smoking cessation interventions are underscored by the unusually high frequency of smoking among the HIV-infected, compounded by an apparent lack of awareness of the heightened associated health risks.

\section{References}

1 World Health Organization. WHO Report on the Global Tobacco Epidemic, 2011. Warning about the dangers of tobacco. http://whqlibdoc.who.int/publications/2011/9789240687813_eng.pdf?ua=1. Date last accessed: August 3, 2014

2 Carter BD, Abnet CC, Feskanich D, et al. Smoking and mortality - beyond established causes. N Engl J Med 2015; 372: 631-640

3 Ng M, Freeman MK, Fleming TD, et al. Smoking prevalence and cigarette consumption in 187 countries, 1980-2012. JAMA 2014; 311: 183-192.

4 Lim SS, Vos T, Flaxman AD, et al. A comparative risk assessment of burden of disease and injury attributable to 67 risk factors and risk factor clusters in 21 regions, 1990-2010: a systematic analysis for the Global Burden of Disease Study 2010. Lancet 2012; 380: 2224-2260.

5 Friis-Møller N, Weber R, Reiss P, et al. Cardiovascular disease risk factors in HIV patients - association with antiretroviral therapy. Results from the DAD study. AIDS 2003; 17: 1179-1193.

6 Clifford GM, Polesel J, Rickenback M, et al. Cancer risk in the Swiss HIV Cohort Study: associations with immunodeficiency, smoking, and highly active antiretroviral therapy. J Natl Cancer Inst 2005; 97: 425-432.

7 Benard A, Bonnet F, Tessier JF, et al. Tobacco addiction and HIV infection: toward the implementation of cessation programs. ANRS CO3 Aquitaine Cohort. AIDS Patient Care STDS 2007; 21: 458-468.

8 Nahvi S, Cooperman NA. Review: the need for smoking cessation among HIV-positive smokers. AIDS Educ Prev 2009; 21: Suppl. 3, 14-27.

9 Tesoriero JM, Gieryic SM, Carrascal A, et al. Smoking among HIV positive New Yorkers: prevalence, frequency, and opportunities for cessation. AIDS Behav 2010; 14: 824-835.

10 Moscou-Jackson G, Commodore-Mensah Y, Farley J, et al. Smoking-cessation interventions in people living with HIV infection: a systematic review. J Assoc Nurses AIDS Care 2014; 25: 32-45.

11 Feldman JG, Minkoff H, Schneider MF, et al. Association of cigarette smoking with HIV prognosis among women in the HAART era: a report from the women's interagency HIV study. Am J Public Health 2006; 96: 1060-1065.

12 Crothers K, Griffith TA, McGinnis KA, et al. The impact of cigarette smoking on mortality, quality of life, and comorbid illness among HIV-positive veterans. J Gen Intern Med 2005; 20: 1142-1145.

13 Benito N, Moreno A, Miro JM, et al. Pulmonary infections in HIV-infected patients: an update in the 21st century. Eur Respir J 2012; 39: 730-745.

14 Miguez-Burbano MJ, Ashkin D, Rodriguez A, et al. Increased risk of Pneumocystis carinii and community-acquired pneumonia with tobacco use in HIV disease. Int J Infect Dis 2005; 9: 208-217.

15 Petrosillo N, Cicalini S. Smoking and HIV: time for a change? BMC Med 2013; 11: 16

16 van Zyl-Smit RN, Brunet L, Pai M, et al. The convergence of the global smoking, COPD, tuberculosis, HIV, and respiratory infection epidemics. Infect Dis Clin North Am 2010; 24: 693-703.

17 van Zyl-Smit RN, Pai M, Yew WW, et al. Global lung health: the colliding epidemics of tuberculosis, tobacco smoking, HIV and COPD. Eur Respir J 2010; 35: 27-33.

18 Rahmanian S, Wewers ME, Koletar S, et al. Cigarette smoking in the HIV-infected population. Proc Am Thorac Soc 2011; 8: 313-319.

19 Helleberg M, Afzal S, Kronborg G, et al. Mortality attributable to smoking among HIV-1-infected individuals: a nationwide, population-based cohort study. Clin Infect Dis 2013; 56: 727-734.

20 Schacker T. The role of secondary lymphatic tissue in immune deficiency of HIV infection. AIDS 2008; 22 ; S13-S18.

21 Brenchley JM, Paiardini M, Knox KS, et al. Differential Th17 CD4 T-cell depletion in pathogenic and nonpathogenic lentiviral infections. Blood 2008; 112: 2826-2835.

22 Mavigner $\mathrm{M}$, Cazabat $\mathrm{M}$, Dubois $\mathrm{M}$, et al. Altered $\mathrm{CD}^{+} \mathrm{T}$ cell homing to the gut impairs mucosal immune reconstitution in treated HIV-infected individuals. J Clin Invest 2012; 122: 62-69.

23 Brenchley JM, Knox KS, Asher AI, et al. High frequencies of polyfunctional HIV-specific T cells are associated with preservation of mucosal CD4 T cells in bronchoalveolar lavage. Mucosal Immunol 2008; 1: 49-58.

24 Jambo KC, Banda DH, Kankwatira AM, et al. Small alveolar macrophages are infected preferentially by HIV and exhibit impaired phagocytic function. Mucosal Immunol 2014; 7: 1116-1126.

25 Segal LN, Methé BA, Nolan A, et al. HIV-1 and bacterial pneumonia in the era of antiretroviral therapy. Proc Am Thorac Soc 2011; 8: 282-287.

26 Perreau M, Levy Y, Pantaleo G. Immune response to HIV. Curr Opin HIV AIDS 2013; 8: 333-340.

27 Monroe KM, Yang Z, Johnson JR, et al. IFI16 DNA sensor is required for death of lymphoid CD4 T cells abortively infected with HIV. Science 2014; 343: 428-432.

28 Perreau M, Savoye AL, De Crignis E, et al. Follicular helper T cells serve as the major CD4 T cell compartment for HIV-1 infection, replication, and production. J Exp Med 2013; 210: 143-156.

29 Herbein G, Khan KA. Is HIV infection a TNF receptor signalling-driven disease? Trends Immunol 2008; 29: 61-67.

30 D'Souza M, Fontenot AP, Mack DG, et al. Programmed death 1 expression on HIV-specific CD4 $4^{+} \mathrm{T}$ cells is driven by viral replication and associated with T cell dysfunction. J Immunol 2007; 179: 1979-1987.

31 Kinter AL, Godbout EJ, McNally JP, et al. The common $\gamma$-chain cytokines IL-2, IL-7, IL-15, and IL-21 induce the expression of programmed death-1 and its ligands. J Immunol 2008; 181: 6738-6746. 
van Grevenynghe J, Cubas RA, Noto A, et al. Loss of memory B cells during chronic HIV infection is driven by Foxo3a- and TRAIL-mediated apoptosis. J Clin Invest 2011; 121: 3877-3888.

Neff CP, Chain JL, MaWhinney S, et al. Lymphocytic alveolitis is associated with the accumulation of functionally impaired HIV-specific T cells in the lung of antiretroviral therapy-naïve subjects. Am J Respir Crit Care Med 2015; 191: 464-473.

Miller E, Bhardwaj N. Dendritic cell dysregulation during HIV-1 infection. Immunol Rev 2013; 254: $170-189$.

Klatt NR, Funderburg NT, Brenchley JM. Microbial translocation, immune activation, and HIV disease. Trends Microbiol 2013; 21: 6-13.

Bowers NL, Helton ES, Huijbregts RP, et al. Immune suppression by neutrophils in HIV-1 infection: role of PD-L1/PD-1 pathway. PLoS Pathog 2014; 10: e1003993.

Cloke T, Munder M, Bergin P, et al. Phenotypic alteration of neutrophils in the blood of HIV seropositive patients. PLoS One 2013; 8: e72034.

Vollbrecht T, Stirner R, Tufman A, et al. Chronic progressive HIV-1 infection is associated with elevated levels of myeloid-derived suppressor cells. AIDS 2012; 26: F31-F37.

Chen W, Konkel JE. TGF- $\beta$ and “adaptive" Foxp3 ${ }^{+}$regulatory T cells. J Mol Cell Biol 2010; 2: 30-36.

Wiercińska-Drapalo A, Flisiak R, Jaroszewicz J, et al. Increased plasma transforming growth factor- $\beta 1$ is associated with disease progression in HIV-1-infected patients. Viral Immunol 2004; 17: 109-113.

Malherbe G, Steel HC, Cassol S, et al. Circulating biomarkers of immune activation distinguish viral suppression from nonsuppression in HAART-treated patients with advanced HIV-1 subtype C infection. Mediators Inflamm 2014; 2014: 198413.

Tange S, Oktyabri D, Terashima M, et al. JARID2 is involved in transforming growth factor-beta-induced epithelial-mesenchymal transition of lung and colon cancer cell lines. PLoS One 2014; 9: e115684.

Chen H, Wang JW, Liu LX, et al. Expression and significance of transforming growth factor- $\beta$ receptor type II and DPC4/Smad4 in non-small cell lung cancer. Exp Ther Med 2015; 9: 227-231.

Yang YC, Zhang N, Van Crombruggen K, et al. Transforming growth factor-betal in inflammatory airway disease: a key for understanding inflammation and remodeling. Allergy 2012; 67: 1193-1202.

Feldman C, Anderson R. Cigarette smoking and mechanisms of susceptibility to infections of the respiratory tract and other organ systems. J Infect 2013; 67: 169-184.

Hasday JD, Bascom R, Costa JJ, et al. Bacterial endotoxin is an active component of cigarette smoke. Chest 1999; 115: 829-835.

Larsson L, Pehrson C, Dechen T, et al. Microbiological components in mainstream and sidestream cigarette smoke. Tob Induc Dis 2012; 10: 13 .

O'Leary SM, Coleman MM, Chew WM, et al. Cigarette smoking impairs human pulmonary immunity to Mycobacterium tuberculosis. Am J Respir Crit Care Med 2014; 190: 1430-1436.

Nyunoya T, Mebratu Y, Contreras A, et al. Molecular processes that drive cigarette smoke-induced epithelial cell fate of the lung. Am J Respir Cell Mol Biol 2014; 50: 471-482.

Schweitzer KS, Hatoum H, Brown MB, et al. Mechanisms of lung endothelial barrier disruption induced by cigarette smoke: role of oxidative stress and ceramides. Am J Physiol Lung Cell Mol Physiol 2011; 301: L836-L846.

Campillo-Gimenez L, Casulli S, Dudoit Y, et al. Neutrophils in antiretroviral therapy-controlled HIV demonstrate hyperactivation associated with a specific IL-17/IL-22 environment. J Allergy Clin Immunol 2014; 134: $1142-1152$.

Van Eeden SF, Hogg JC. The response of human bone marrow to chronic cigarette smoking. Eur Respir J 2000; 15: 915-921.

Van Eeden S, Leipsic J, Man SFP, et al. The relationship between lung inflammation and cardiovascular disease. Am J Respir Crit Care Med 2012; 186: 11-16.

Valiathan R, Miguez MJ, Patel B, et al. Tobacco smoking increases immune activation and impairs T-cell function in HIV infected patients on antiretrovirals: a cross-sectional pilot study. PLoS One 2014; 9: e97698.

Barbieri SS, Zacchi E, Amadio P, et al. Cytokines present in smokers' serum interact with smoke components to enhance endothelial dysfunction. Cardiovasc Res 2011; 90: 475-483.

Anderson R, Tintinger GR, Feldman C. Inflammation and cancer: the role of the human neutrophil. S Afr J Sci 2014; 110 [DOI: 10.1590/ sajs.2014/20130207].

Takizawa $\mathrm{H}$, Tanaka $\mathrm{M}$, Takami $\mathrm{K}$, et al. Increased expression of transforming growth factor- $\beta 1$ in small airway epithelium from tobacco smokers and patients with cronic obstructive pulmonary disease (COPD). Am J Respir Crit Care Med 2001; 163: 1476-1483.

Abbud RA, Finegan CK, Guay LA, et al. Enhanced production of human immunodeficiency virus type 1 by in vitro-infected alveolar macrophages from otherwise healthy cigarette smokers. J Infect Dis 1995; 172: 859-863.

Rock RB, Gekker G, Aravalli RN, et al. Potentiation of HIV-1 expression in microglial cells by nicotine: involvement of transforming growth factor- $\beta 1$. J Neuroimmune Pharmacol 2008; 3: 143-149.

Zhao L, Li F, Zhang Y, et al. Mechanisms and genes involved in enhancement of HIV infectivity by tobacco smoke. Toxicology 2010; 278: 242-248.

Popescu I, Drummond MB, Gama L, et al. Activation-induced cell death drives profound CD4 ${ }^{+}$T-cell depletion in HIV-associated chronic obstructive pulmonary disease. Am J Respir Crit Care Med 2014; 190: 744-755.

Twigg HL, Knox KS. Impact of antiretroviral therapy on lung immunology and inflammation. Clin Chest Med 2013; 34: 155-164.

Corre F, Lellouch J, Schwartz D. Smoking and leucocyte-counts. Results of an epidemiological survey. Lancet 1971; 2: 632-634.

Arcavi L, Benowitz NL. Cigarette smoking and infection. Arch Intern Med 2004; 164: 2206-2216.

Park LP, Margolick JB, Giorgi JV, et al. Influence of HIV-1 infection and cigarette smoking on leukocyte profiles in homosexual men. The Multicenter AIDS Cohort Study. J Aquir Immune Defic Synd 1992; 5: 1124-1130.

Royce RA, Winkelstein W Jr. HIV infection, cigarette smoking and CD4+ T-lymphocyte counts: preliminary results from the San Francisco Men's Health Study. AIDS 1990; 4: 327-323.

Nieman RB, Fleming J, Coker RJ, et al. The effect of cigarette smoking on the development of AIDS in HIV-1 seropositive individuals. AIDS 1993; 7: 705-710. 
Mellors JW, Muñoz A, Giorgi JV, et al. Plasma viral load and CD4+ lymphocytes as prognostic markers of HIV-1 infection. Ann Intern Med 1997; 126: 946-954.

Boelaert JR, Piette J, Weinberg GA, et al. Iron and oxidative stress as a mechanism for the enhanced production of human immunodeficiency virus by alveolar macrophages from otherwise healthy cigarette smokers. J Infect Dis 1996; 173: 1045-1047.

Ande A, McArthur C, Kumar A, et al. Tobacco smoking effect on HIV-1 pathogenesis: role of cytochrome P450 isozymes. Expert Opin Drug Metab Toxicol 2013; 9: 1453-1464.

Burns DN, Kramer A, Yellin F, et al. Cigarette smoking: a modifier of human immunodeficiency virus type 1 infection? J Acquir Immune Defic Syndr 1991; 4: 76-83.

Craib KJ, Schecter MT, Montaner JS, et al. The effect of cigarette smoke on lymphocyte subsets and progression to AIDS in a cohort of homosexual men. Clin Invest Med 1992; 15: 301-308.

Conley LJ, Bush TJ, Buchbinder KA, et al. The association between cigarette smoking and selected HIV-related medical conditions. AIDS 1996; 10: 1121-1126.

Galai N, Park LP, Wesch J, et al. Effect of smoking on the clinical progression of HIV-1 infection. J Acquir Immune Defic Syndr Hum Retrovirol 1997; 14: 451-458.

Coates RA, Farewell VT, Raboud J, et al. Cofactors of progression to acquired immunodeficiency syndrome in a cohort of male sexual contacts of men with human immunodeficiency virus disease. Am J Epidemiol 1990; 132: 717-722.

Eskild A, Petersen G. Cigarette smoking and drinking of alcohol are not associated with rapid progression to acquired immunodeficiency syndrome among homosexual men in Norway. Scand J Soc Med 1994; 3: $209-212$.

Study Group for the MRC Collaborative Study of HIV infection in Women. Survival and progression of HIV disease in women attending GUM/HIV clinics in Britain and Ireland. Sex Transm Infect 1999; 75: 247-252.

Webber MP, Schoenbaum EE, Gourevitch MN, et al. A prospective study of HIV disease progression in female and male drug users. AIDS 1999; 13: 257-262.

Marshall MM, McCormack MC, Kirk GD. Effect of cigarette smoking on HIV acquisition, progression, and mortality. AIDS Educ Prev 2009; 21: Suppl. 3, 28-39.

Miguez-Burbano MJ, Burbano X, Ashkin D, et al. Impact of tobacco use on the development of opportunistic respiratory infections in HIV seropositive patients on antiretroviral therapy. Addict Biol 2003; 8: 39-43.

Yuan Y, L'italien G, Mukherjee J, et al. Determinants of discontinuation of initial highly active antiretroviral therapy regimens in a US HIV-infected patient cohort. HIV Med 2006; 7: 156-162.

Shuter J, Bernstein SL. Cigarette smoking is an independent predictor of nonadherence in HIV-infected individuals receiving highly active antiretroviral therapy. Nicotine Tob Res 2008; 10: 731-736.

Read TRH, Carey D, Mallon P, et al. Efavirenz plasma concentrations did not predict cessation of therapy due to neuropsychiatric symptoms in a large randomized trial. AIDS 2009; 23: 2222-2223.

Feldman DN, Feldman JG, Greenblatt R, et al. CYP1A1 genotype modifies the impact of smoking on effectiveness of HAART among women. AIDS Educ Prev 2009; 21: 81-93.

Rahmioglu N, Heaton J, Clement G, et al. Genetic epidemiology of induced CYP3A4 activity. Pharmacogenet Genomics 2011; 21: 642-651.

D'Arcy PF. Tobacco smoking and drugs: a clinically important interaction? Drug Intell Clin Pharm 1984; 18: 302-307.

Dickinson L, Khoo S, Back D. Pharmacokinetics and drug-drug interactions of antiretrovirals: an update. Antiviral Res 2010; 85: 176-189.

Tseng AL, Foisy MM. Significant interactions with new antiretrovirals and psychotropic drugs. Ann Pharmacother 1999; 33: 461-473.

Varela-Carver A, Parker H, Kleinert C, et al. Adverse effects of cigarette smoke and induction of oxidative stress in cardiomyocytes and vascular endothelium. Curr Pharm Des 2010; 16: 2551-2558.

López S, Miró O, Martínez E, et al. Mitochondrial effects of antiretroviral therapies in asymptomatic patients. Antivir Ther 2004; 9: 47-55.

Tharappel JC, Cholewa J, Espandiari P, et al. Effects of cigarette smoke on the activation of oxidative stress-related transcription factors in female A/J mouse lung. J Toxicol Environ Health A 2010; 73: $1288-1297$.

Fantuzzi L, Conti L, Gauzzi MC, et al. Regulation of chemokine/cytokine network during in vitro differentiation and HIV-1 infection of human monocytes: possible importance in the pathogenesis of AIDS. J Leukoc Biol 2000; 68: 391-399.

Madeddu G, Porqueddu EM, Cambosu F, et al. Bacterial community acquired pneumonia in HIV-infected inpatients in the highly active antiretroviral therapy era. Infection 2008; 36: 231-236.

Gordin FM, Roediger MP, Girard PM, et al. Pneumonia in HIV-infected persons: increased risk with cigarette smoking and treatment interruption. Am J Respir Crit Care Med 2008; 178: 630-636.

Nair GB, Niederman MS. Community-acquired pneumonia: an unfinished battle. Med Clin North Am 2011; 95: 1143-1161.

Reynolds JH, McDonald G, Alton H, et al. Pneumonia in the immunocompetent patient. Br J Radiol 2010; 83: 998-1009.

Feldman C, Anderson R. HIV-associated bacterial pneumonia. Clin Chest Med 2013; 34: 205-216. a literature review. Thorax 2013; 68: 1057-1065.

Brown J, Lipman M. Community-acquired pneumonia in HIV-infected individuals. Curr Infect Dis Rep 2014; 16: 397.

Raju R, Peters BS, Breen RA. Lung infections in the HIV-infected adult. Curr Opin Pulm Med 2012; 18: 253-258. Grau I, Ardanuy C, Calatayud L, et al. Smoking and alcohol abuse are the most preventable risk factors for invasive pneumonia and other pneumococcal infections. Int J Infect Dis 2014; 25: 59-64.

2 Bénard A, Mercié P, Alioum A, et al. Bacterial pneumonia among HIV-infected patients: decreased risk after tobacco smoking cessation. ANRS CO3 Aquitaine Cohort, 2000-2007. PLoS One 2010; 5: e8896.

Crothers K, Tindle HA. Prevention of bacterial pneumonia in HIV infection: focus on smoking cessation. Expert Rev Anti Infect Ther 2011; 9: 759-762. 
104

105

106

De P, Farley A, Lindson N, et al. Systematic review and meta-analysis: influence of smoking cessation on incidence of pneumonia in HIV. BMC Med 2013; 11: 15.

Gajalakshmi V, Peto R, Kanaka TS, et al. Smoking and mortality from tuberculosis and other diseases in India: retrospective study of 43000 adult male deaths and 35000 controls. Lancet 2003; 362: 507-515.

Leung CC, Li T, Lam TH, et al. Smoking and tuberculosis among the elderly in Hong Kong. Am J Respir Crit Care Med 2004; 170: 1027-1033.

Jee SH, Golub JE, Jo J, et al. Smoking and risk of tuberculosis incidence, mortality, and recurrence in South Korean men and women. Am J Epidemiol 2009; 170: 1478-1485.

Lin HH, Ezzati M, Chang HY, et al. Association between tobacco smoking and active tuberculosis in Taiwan: prospective cohort study. Am J Respir Crit Care Med 2009; 180: 475-480.

Wang J, Shen H. Review of cigarette smoking and tuberculosis in China: intervention is needed for smoking cessation among tuberculosis patients. BMC Public Health 2009; 9: 292.

Brunet L, Pai M, Davids V, et al. High prevalence of smoking among patients with suspected tuberculosis in South Africa. Eur Respir J 2011; 38: 139-146.

Bonacci RA, Cruz-Hervert LP, García-García L, et al. Impact of cigarette smoking on rates and clinical prognosis of pulmonary tuberculosis in Southern Mexico. J Infect 2013; 66: 303-312. from a cross-sectional study in central India. Trans R Soc Trop Med Hyg 2014; 108: 474-481.

Altet-Gómez MN, Alcaide J, Godoy P, et al. Clinical and epidemiological aspects of smoking and tuberculosis: a study of 13038 cases. Int J Tuberc Lung Dis 2005; 9: 430-436.

Tachfouti N, Nejjari C, Benjelloun MC, et al. Association between smoking status, other factors and tuberculosis treatment failure in Morocco. Int J Tuberc Lung Dis 2011; 15: 838-843.

Siddiqui UA, O’Toole M, Kabir Z, et al. Smoking prolongs the infectivity of patients with tuberculosis. Ir Med J 2010; 103: 278-280.

Maciel EL, Brioschi AP, Peres RL, et al. Smoking and 2-month culture conversion during anti-tuberculosis treatment. Int J Tuberc Lung Dis 2013; 17: 225-228.

Pefura-Yone EW, Kengne AP, Kuaban C. Non-conversion of sputum culture among patients with smear positive pulmonary tuberculosis in Cameroon: a prospective cohort study. BMC Infect Dis 2014; 14: 138.

Yen YF, Yen MY, Lin YS, et al. Smoking increases risk of recurrence after successful anti-tuberculosis treatment: a population-based study. Int J Tuberc Lung Dis 2014; 18: 492-498.

Keshavjee S, Gelmanova IY, Shin SS, et al. Hepatotoxicity during treatment for multidrug-resistant tuberculosis: occurrence, management and outcome. Int J Tuberc Lung Dis 2012; 16: 596-603.

Plit ML, Anderson R, Van Rensburg CEJ, et al. Influence of antimicrobial chemotherapy on spirometric parameters and pro-inflammatory indices in severe pulmonary tuberculosis. Eur Respir J 1998; 12: 351-356.

Vanden Driessche K, Patel MR, Mbonze N, et al. Effects of smoking history on outcome of patients diagnosed with TB and HIV. Eur Respir J 2015; 45: 839-842.

Chung-Delgado K, Revilla-Montag A, Guillen-Bravo S, et al. Factors associated with anti-tuberculosis medication adverse effects: a case-control study in Lima, Peru. PLoS One 2011; 6: e27610.

Zaverucha-do-Valle C, Monteiro SP, El-Jaick KB, et al. The role of cigarette smoking and liver enzymes polymorphisms in anti-tuberculosis drug-induced hepatotoxicity in Brazilian patients. Tuberculosis 2014; 94: 299-305.

Morris A, Kingsley L, Groner G, et al. Prevalence and clinical predictors of Pneumocystis colonization among HIV-infected men. AIDS 2004; 18: 793-798.

Murin S, Bilello KS, Matthay R. Other smoking-affected pulmonary diseases. Clin Chest Med 2000; 21: 121-137. Murin S, Bilello KS. Respiratory tract infections: another reason not to smoke. Cleve Clin J Med 2005; 72: 916-920.

Lenzi L, Mello ÂM, Silva LR, et al. Pandemic influenza A (H1N1) 2009: risk factors for hospitalization. J Bras Pneumol 2012; 38: 57-65.

Lowcock EC, Rosella LC, Foisy J, et al. The social determinants of health and pandemic H1N1 2009 influenza severity. Am J Public Health 2012; 102: e51-e58.

Wong CM, Yang L, Chan KP, et al. Cigarette smoking as a risk factor for influenza-associated mortality: evidence from an elderly cohort. Influenza Other Respir Viruses 2013; 7: 531-539.

Cohen C, Moyes J, Tempia S, et al. Severe influenza-associated respiratory infection in high HIV prevalence setting, South Africa, 2009-2011. Emerg Infect Dis 2013; 19: 1766-1774.

Hajjeh RA, Conn LA, Stephens DS, et al. Cryptococcosis: population-based multistate active surveillance and risk factors in human immunodeficiency virus-infected persons. J Infect Dis 1999; 179: 449-454.

MacDougall L, Fyfe M, Romney M, et al. Risk factors for Cryptococcus gattii infection, British Columbia, Canada. Emerg Infect Dis 2011; 17: 193-199.

Winstone TA, Man SF, Hull M, et al. Epidemic of lung cancer in patients with HIV infection. Chest 2013; 143: 305-314.

4 Bower M, Powles T, Nelson M, et al. HIV-related lung cancer in the era of highly active antiretroviral therapy. AIDS 2003; 17: 371-375.

Cadranel J, Garfield D, Lavolé A, et al. Lung cancer in HIV infected patients: facts, questions and challenges. Thorax 2006; 61: 1000-1008.

Engels EA, Brock MV, Chen J, et al. Elevated incidence of lung cancer among HIV-infected individuals. $J$ Clin Oncol 2006; 24: 1383-1388.

7 Kirk GD, Merlo C, O'Driscoll P, et al. HIV infection is associated with an increased risk for lung cancer, independent of smoking. Clin Infect Dis 2007; 45: 103-110.

Kirk GD, Merlo CA, Lung HIV Study. HIV infection in the etiology of lung cancer: confounding, causality, and consequences. Proc Am Thorac Soc 2011; 8: 326-332.

Clifford GM, Lise M, Franceschi S, et al. Lung cancer in the Swiss HIV Cohort Study: role of smoking, immunodeficiency and pulmonary infection. Br J Cancer 2012; 106: 447-452.

Sigel K, Wisnivesky J, Gordon K, et al. HIV as an independent risk factor for incident lung cancer. AIDS 2012; 26: $1017-1025$. 
Gingo MR, Morris A. Pathogenesis of HIV and the lung. Curr HIV/AIDS Rep 2013; 10: 42-50.

Morris A, Norris KA. Colonization by Pneumocystis jirovecii and its role in disease. Clin Microbiol Rev 2012; 25: 297-317.

Liang HY, Li XL, Yu XS, et al. Facts and fiction of the relationship between preexisting tuberculosis and lung cancer risk: a systematic review. Int J Cancer 2009; 125: 2936-2944.

Zhan P, Suo LJ, Qian Q, et al. Chlamydia pneumoniae infection and lung cancer risk: a meta-analysis. Eur J Cancer 2011; 47: 742-747.

Diaz PT, King MA, Pacht ER, et al. Increased susceptibility to pulmonary emphysema among HIV-seropositive smokers. Ann Intern Med 2000; 132: 369-372.

Morris A, George MP, Crothers K, et al. HIV and chronic obstructive pulmonary disease: is it worse and why? Proc Am Thorac Soc 2011; 8: 320-325.

Drummond MB, Kirk GD, Astemborski J, et al. Association between obstructive lung disease and markers of HIV infection in a high-risk cohort. Thorax 2012; 67: 309-314.

Crothers K, Butt AA, Gibert CL, et al. Increased COPD among HIV-positive compared to HIV-negative veterans. Chest 2006; 130: 1326-1333.

Diaz PT, Clanton TL, Pacht ER. Emphysema-like pulmonary disease associated with human immunodeficiency virus infection. Ann Intern Med 1992; 116: 124-128.

Attia EF, Akgün KM, Wongtrakool C, et al. Increased risk of radiographic emphysema in HIV is associated with elevated soluble CD14 and nadir CD4. Chest 2014; 146: 1543-1553.

Kang MJ, Lee CG, Lee JY, et al. Cigarette smoke selectively enhances viral PAMP- and virus-induced pulmonary innate immune and remodeling responses in mice. J Clin Invest 2008; 118: 2771-2784.

Immunol Res 2011; 50: 175-180.

28: $575-587$.

Raynaud C, Roche N, Chouaid C. Interactions between HIV infection and chronic obstructive pulmonary disease: clinical and epidemiological aspects. Respir Res 2011; 12: 117.

U.S. National Institutes of Health. Strategic timing of antiretroviral treatment (START). https://clinicaltrials.gov/ ct2/show/NCT00867048 Date last accessed: April 20, 2015. Date last updated: January 14, 2015.

Verghese A, al-Samman M, Nabhan D, et al. Bacterial bronchitis and bronchiectasis in human immunodeficiency virus infection. Arch Intern Med 1994; 154: 2086-2091.

Holmes AH, Trotman-Dickenson B, Edwards A, et al. Bronchiectasis in HIV disease. Q J Med 1992; 85: 875-882.

Almodovar S, Cicalini S, Petrosillo N, et al. Pulmonary hypertension associated with HIV infection. Pulmonary vascular disease: the global perspective. Chest 2010; 137: Suppl. 6, 6S-12S.

Hsue PY, Deeks SG, Farah HH, et al. Role of HIV and human herpesvirus-8 infection in pulmonary arterial hypertension. AIDS 2008; 22: 825-833.

Sandler NG, Wand H, Roque A, et al. Plasma levels of soluble CD14 independently predict mortality in HIV infection. J Infect Dis 2011; 203: 780-790.

61 Cioe PA, Baker J, Hammer J, et al. Soluble CD14 and d-dimer are associated with cigarette smoking and alcohol use in HIV-infected adults. Abstract 732. 21st Conference on Retroviruses and Opportunistic Infections. Boston, MA, USA. March 3-6, 2014. www.croiconference.org/sites/all/abstracts/732.pdf. Date last accessed: April $20,2015$. Krishnan S, Bosch RJ, Rodriguez B, et al. Correlates of inflammatory markers after one year of suppressive antiretroviral treatment (ART). Abstract 757. 21st Conference on Retroviruses and Opportunistic Infections Boston, MA, USA. March 3-6, 2014. www.croiconference.org/sites/all/abstracts/757.pdf. Date last accessed: April $20,2015$.

63 French MA, King MS, Tschampa JM, et al. Serum immune activation markers are persistently increased in patients with HIV infection after 6 years of antiretroviral therapy despite suppression of viral replication and reconstitution of CD4 ${ }^{+} \mathrm{T}$ cells. J Infect Dis 2009; 200: 1212-1215.

Rajasuriar R, Khoury G, Kamarulzaman A, et al. Persistent immune activation in chronic HIV infection: do any interventions work? AIDS 2013; 27: 1199-1208

d'Ettorre G, Paiardini M, Ceccarelli G, et al. HIV-associated immune activation: from bench to bedside. AIDS Res Hum Retroviruses 2011; 27: 355-364.

Doitsh G, Galloway NLK, Geng X, et al. Cell death by pyroptosis drives CD4 T-cell depletion in HIV-1 infection. Nature 2014; 505: 509-514. 